\title{
Bridging the Distance by New Forms of Technology-Supported Learning: Is it Enough?
}

\section{Theodore Fernando*}

Professor, Open University of Sri Lanka, Sri Lanka

\begin{abstract}
The Social Studies Department of the Open University of Sri Lanka has administered the B.A. Degree in Social science for the past two decades. With a generous World Bank Grant known as the Quality Innovative Grant, (QIG), two years ago, we were able to up-grade our existing B.A. Degree program and introduce a series of new subjects in keeping with the demands of the industry and the students. The use of I.M.M (interactive multi-media), S.M.S. alerts, many online courses, video conferences, and a digital dictionary were some of the new technological supported learning that were introduced under this World Bank Grant. However, the students' response was not very encouraging. Instead of studying with supported teaching by using technology, most of the students used the method of, "cut and paste" from the Wikipedia and some also opted to drop out from the degree. In order to find why this was happening, a qualitative research method, namely a focus group discussion was conducted among the visiting academics of the regional centers.

According to the answers given, one of the main disadvantages of distance learning is the absence of social interaction among students who are enrolled in study programs. Unlike in the conventional universities, often students miss the privilege of social interaction with teachers and their peers. Another drawback mentioned is that distance learning is an inappropriate format for everyone though many like to enroll. Due to the limited intake in the conventional universities in Sri Lanka, without inquiring about the suitability of distant learning, a number of young people tend to enroll with the Open University as a kind of a novelty. However, not everyone is suitable for enrollment in distant programs especially if a person tends to lag behind his/her work, lacks motivation and requires individual coaching from the teacher. It is a fact that some students learn only when they are physically present in the class and assimilating all the information personally. Many visiting academics admitted that technical innovations alone were not very helpful especially to motivate students. To bridge the gap of distance, there is a need for new forms of technology-supported learning and effective distance learning instructors. However, New Technology alone is not sufficient. Finding the right solution is a daunting task for academics who use Distance Education to teach in Sri Lanka.
\end{abstract}

Keywords: Social; Education; Environment; Technology

\section{Introduction}

Distance learning allows for a personalized learning experience with regard to the individual interests, achievement level, life circumstance and goals of each student. May be accessed from anywhere, at any time, and at any pace, in accordance with the individual needs of each student. It is an educational method that focuses on delivering classroom content/instruction to students who are not physically on site. Instead, teachers and students communicate either asynchronously (at a time of their own choosing via email or other text based communication which is also known as a print tutor), or using technology that allows them to communicate in real time (synchronously).

Many variants of distance learning include e-learning, mobile learning, and immersive learning environments. Today, distance learning is enhanced or strengthened by emerging or new forms of technologies. These technologies have been proclaimed as providing the opportunities and affordances to transform education, learning and teaching. According to Veletsianos emerging technologies can be correctly defined as tools, concepts, innovations and advancements that are used in diverse educational settings to serve various education related purposes [1]. According to scholars though technological innovations and advancements definitely have brought a massive transformation in the society at large, relatively technology's impact on education, teaching, and learning is rather disappointing or limited [2]. Further, according to Cuban, while expectations were high about instructional radio, television, personal computers, computer-based instruction, the Internet, Web 2.0, e learning, m-learning, and latest state of the art equipment, have often proved disappointing [3]. Cuban further, holds the view that "showcase" learning environments, technology supported learning that merely replicates face-to-face, teaching of day schools, seems to disengage the majority of students.

However, in looking at the advantages or the positive side of new technologies in their special edition of the Journal of Interactive Media in Education, especially in the introduction of their issue provide an overview of three affordances of the Web [4]. The first is the capacity for powerful yet very low-cost communications. According to them, this capacity forms the platform upon which "epistemic-engagement" visions of learning are initiated. Communications may be expressed through text, voice, video, or even immersive interaction modes. Some of these communication modes can also be combined in many creative ways. Communication artifacts can be stored, indexed, tagged, harvested, searched, and stored. The second affordance mentioned by Whitelock and Anderson is that the Net creates a context that moves learners from information and content scarcity to abundance [4].

*Corresponding author: Theodore Fernando, Open University of Sri Lanka, Sri Lanka, Tel: +94 112 881000; E-mail: Fernando.theodore2@gmail.com

Received May 18, 2018; Accepted June 20, 2018; Published June 27, 2018

Citation: Fernando T (2018) Bridging the Distance by New Forms of TechnologySupported Learning: Is it Enough?. Arts Social Sci J 9: 370. doi: 10.4172/21516200.1000370

Copyright: () 2018 Fernando T. This is an open-access article distributed under the terms of the Creative Commons Attribution License, which permits unrestricted use, distribution, and reproduction in any medium, provided the original author and source are credited. 
This includes from early-learning object repositories to wide-scale distribution and production of Open Educational Resources from many networked sites, and the Net provides learning content with many different display and presentation attributes. This content exists in many formats, and often uses multimedia to enhance its presentational value. According to Burns most exciting is the capacity for learners and teachers to add user-created content and to edit and enhance the work of others using produsage production modes [5]. The third affordance articulated by Whitelock and Andersion is the affordance of active and autonomous agents found in the Net, to gather, aggregate, synthesize, and filter the Net for content communications that is relevant to individual and groups of learners and teachers [4]. According to Ellison et al., Net-infused learning does not entail desertion of one's physical spaces, but rather serves to facilitate, document, and deepen place-based communication and relationships [6]. Mejias' research points to the need for blended applications in which networks are used for teaching and learning when appropriate and offer particular access, time shifting, or pedagogical advantage [7]. Looking at both sides namely advantages and disadvantages of new forms of technology one of the objectives of this research paper is to ascertain why there are considerable dropouts or an increase of iqncomplete student rates in the B.A. social sciences offered by the department of social science even after introducing innovative changes by using technology which benefit students.

\section{Literature Review}

According to research distance learners have been shown to have the highest risk of dropping out of their programs of study at tertiary education institutions [8]. A phenomenon that can be largely attributed to the isolation experienced by these students [8-13] in which usually, students desire a sense of being a part of a larger university community, rather than simply being an enrollee or statistic in a course.

Therefore, the distance factor inherent in distance education has been identified as one of the major problems for students studying in this mode $[14,15]$. This geographic isolation significantly detracts from the need for social interactions that are usually afforded by face-to-face situations. On top of the practical problems of contacting academic and administrative staff, obtaining study materials on time, and gaining immediate access to resources such as laboratory equipment and library books, distance learners endure the disadvantage of being unable to interact in person with other students, which can cause a significant damper on their motivation and enthusiasm for study. As such, they are very often denied a sense of belonging to a scholarly community $[16,17]$. The feeling of isolation derives from the distance learner's psychological perception of detachment from the instructor, peers, institution and resource materials. Often times the feeling of isolation is determinant of the learner's success or failure [18].

Thus, great emphasis should to be given to the need to mitigate isolation issues by increasing the opportunities of dialogue among all parties within the design and practice. Isolation decreases with the learner's perception of availability of instructor, peers, administrative staff and resources as well the degree of connectedness (engagement) among them [19].

Another related concern for the distance learner is the perceived lack of contact with and timely feedback from an instructor. To an even greater extent than other students, distance learners are likely to have insecurities about learning Knapper and need both a level of guidance as well as assurance that they are on the right track [20]. Without this support, they may face difficulty in self-evaluating their progress and their understanding of the subject material. Time management too, can become a problem as they invest inordinate amounts of their study time in activities deemed unimportant or less important by the instructor, or in futile searches for answers to queries that could have been clarified or resolved in a matter of minutes by asking a simple verbal question in a conventional university. Such issues therefore, can lead to considerable frustration with the distance education experience, and result in feelings of inadequacy as well as a lack of self-confidence [21].

Over the last few decades, a large number of students have been entering universities with little idea of the institution's culture and few avenues enabling them to acculturate [22]. According to Lake, these students include "recyclers" seeking to upgrade their vocational or industry qualifications; "deferrers," who failed to take up offers of university places upon graduation from high school; "returners," who discontinued their initial university studies, often as a result of perceived isolation; and "early school leavers," who typically have negative memories of their past educational experiences [11]. In his seminal work on distance education, Keegan asserts that the separation of students and teacher removes a vital link of communication between two parties, which must be restored by means of explicit steps to "re-integrate" the teacher-learner interaction, albeit somewhat artificially, through measures such as ongoing electronic or telephone communication [23]. In the absence of these measures, distance students are less likely to undergo acculturation into institutional life and more likely to drop out.

This problem is compounded by the fact that many of these new students may have little or no experience with tertiary study in general, or have had prolonged absence from study. Unless they quickly develop academic "survival skills", these students are at a considerable risk of withdrawing or failing [21]. Of particular importance is the design of distance study materials and learning activities which must carefully consider the special needs of these students $[14,24,25]$. Galusha has done an excellent job of presenting a broad overall picture of the above mentioned and other issues by listing six major categories of problems from the distance student's perspective:

- Balance between costs (monetary and time) and motivators;

- Availability of feedback and teacher contact;

- Access to student support and services;

- Feelings of isolation and alienation;

- Lack of experience (in tertiary study and/or studying at a distance ); and

- Lack of (technical) training.

Accordingly, Garrison emphasizes the importance of social presence, which he proposes is the extent to which remote communicators can project themselves to others using any given technology or medium [26]. Much research has been devoted to the creation and maintenance of social presence in technology-mediated distance learning environments [27]. Without this dimension of connectivity between learners, in addition to teacher presence and rapport, distance learners will often flounder, become increasingly frustrated, and may ultimately withdraw and fail. The tendency and preference for people to work together in groups is a central tenet of social presence theory, so the model is of greater interest to distance educators. According to when social presence levels are low, group members feel disconnected, social cohesion is lessened, and group dynamics are weaker [28]. Conversely, 
when social presence is high, members, tend to feel more connected and engaged, and are motivated to participate in group processes such as collaborative learning. Research also shows that both individuals and groups will be better placed to accept technology-mediated communication as a substitute for face-to-face communication if social presence is high. The successful distance mode student needs to have a number of characteristics such as tolerance for ambiguity, a need for autonomy, and an ability to be flexible [29]. Hardy and Boaz, found that "compared to most face-to-face learning environments, distance learning requires students to be more focused, better time managers, and to be able to work independently and with group members" [30].

As indicated before, distance education students need to feel a part of a community. If they are left alone to themselves, students in these communities often feel less pressure to perform individually, and more pressure to collaborate and be part of the team [31]. Being involved in a collaborative learning process is an important part of forming the foundation of a learning community. When this is not encouraged, participation is generally low and dialog is absent [32]. Students also need the attention of the committed instructors. This is very much warranted in a distance situation than in a traditional classroom. In situations where eye contact and proximity are limited, students cannot be disciplined nor affirmed by eye contact and body language [33].

Therefore, according to the above mentioned studies the "distance" of the distance mode of teaching is one of the universal problems faced by students, studying in Open Universities. How do these problems affect students, studying social sciences at the Open University Sri Lanka?

\section{Conceptual Framework}

"Distance teaching theory" articulated by Holmberg, states that distance teaching will support student motivation and promote learning pleasure and effectiveness if learners are engaged in discussions and decisions, and the technological programmes provide for real and simulated communication to and from the students $[34,35]$. As in any normal classroom, interaction is the core of teaching. Distance education is believed to work very well, and produce results as effective as traditional classroom instruction [36]. However, the distance education currently in practice, specially in the first world, has the potential to provide more effective learning with updated pedagogy, more experience, and greater understanding and knowledge of methods. Moore and Thompson, is of the opinion that improved distance education practices using forms of new technologies have the potential to enhance educational outcomes, especially when the amount and type of learner interaction is increased and there is student to student interaction and teacher to student feedback [37]. Wagner believes that distance learning practitioners tend to view interaction as the "single most significant attribute that defines a contemporary distance learning experience" [38]. Gilbert and Moore, note that an accepted definition of 'interactivity' in the literature on computermediated instruction is a reciprocal exchange between the technology and the learner, a process which they say is referred to as "feedback" [39]. Sherry holds that 'interactivity' takes many forms; it is not just limited to audio and video, nor solely to teacher-student interactions [40]. It represents the connectivity the students feel with the distance education lecturer, the facilitators and their peers. Sherry, further, states that without connectivity, distance learning degenerates into the old correspondence course model of independent study [40]. The student becomes autonomous and isolated, and eventually drops out. She argues that effective distance education should not be independent and isolated from learning, but should approach Keegan's ideal of an authentic learning experience, namely that the distance learning system must artificially recreate the teaching-learning interaction and re-integrate it back into the instructional process.

Keeping the above points as background, this paper looks into the problems faced by the department of social studies in the open university of Sri Lanka with regard to the students and distance teaching.

\section{Significance of the Study}

The Social Studies Department of the Open University of Sri Lanka has administered the B.A. Degree in Social science for the past two decades. The mode of teaching was Print tutor, accompanied by a number of day schools. The Teaching method was traditional, mainly text books, revised sessions, delivery was based on the transmission model. The drop outs were also quite common, and there were also a large number of students who gained incomplete status due to various reasons. The following Figure 1 shows the available figures of drop outs in a graph form in the year 2014 (Figures 1-3).

This was an enigmatic issue for most of the academics, and serious

\section{SSU 1201: Communication Studies}

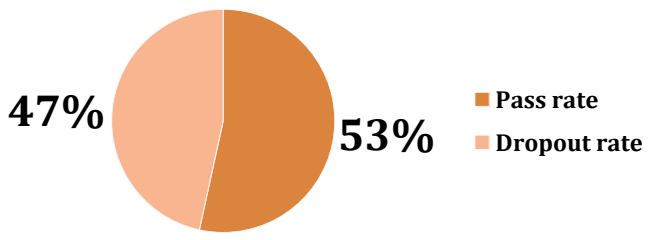

Figure 1: SSU 1201: Communication studies.

\section{SSU 1203: ECONOMICS}

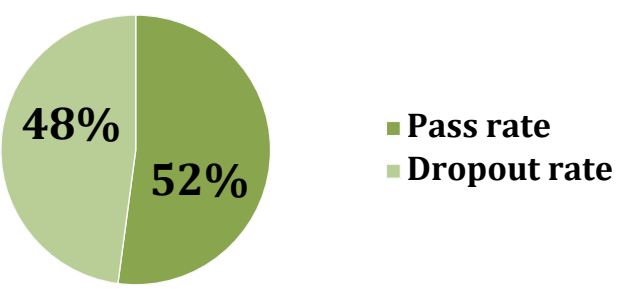

Figure 2: SSU 1203: Economics.

\section{SSU 1205: Sociology}

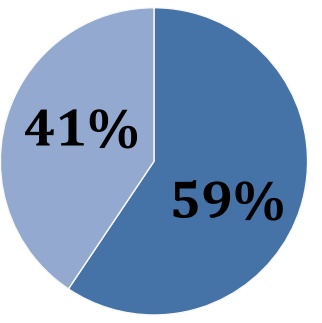

- Pass rate

Dropout rate 
attention has to be paid why this was happening? Various ad hoc solutions were applied but without much effect. As concerned academics using open and distance learning, various solutions were applied including tutor clinics, tailor made orientation sessions, success narratives related by past successful students and availability of past question papers, model answers and new types of assessment methods $[41,42]$.

In addition, with a generous grant of the World Bank known as the Quality Innovative Grant, (QIG), two years ago, which was won on with competing with other conventional universities in Sri Lanka, the department of social science was able to up-grade the existing B.A. Degree program and introduce a series of new subjects in keeping with the demands of the industry and the students and appraisal of the exiting degree. The department was able to introduce new forms of technology to improve and enhance the quality and to motivate students. Introducing of three types of courses, namely traditional, IMM (interactive multi-media) and Online, use of multimedia, S.M.S. alerts, many online courses, and a digital dictionary were some of the new technological supported learning that were introduced under this World Bank Grant. More specifically, innovations included, I.M.M, limited texts supported with selected audio-visual material and marking of the assignments in the regions itself, instead of sending to the main center in the capital. All of these courses were delivered through Moodle [43,44]. Video conferencing was also tried as an innovation or a novelty. However, the students response especially in the regions as well as the main center was not so encouraging. Instead of taking the courses, and assignments seriously, most of the students used the easiest way out namely "cut and paste" from the Wikipedia and some also opted to drop out from the degree. Incomplete status numbers also started to grow. Most of the students were also not reading the given lesson materials at home before attending the limited day schools. Though some subjects were offered as a blended course, there were not much enthusiasm or interaction. Only few students make use of the Moodle to pose questions or comments.

\section{Research Questions}

- Why are the registered students dropping out or discontinuing their studies after enrolling?

- What can the academics/visiting academics do to stop the dropout and discontinuation of the degree by the students?

- Will the new technology help retention of the students and motivate existing students or demotivate?

- What remedies can be suggested to improve the situation?

\section{The research design and method}

a) For the purpose of this case study, a qualitative method, namely focus group, using a purposive sample was employed. Results of the design are outlined as indicated below:

b) A literature review with particular reference to the problems of distance learning, and advantages and disadvantages of new forms of technologies were made.

\section{Data collection}

Qualitative research method, namely a focus group discussion with visiting academics, including some regional directors were made.

\section{The instrument}

The study was done by means of focus group interviews with the visiting academics of the regional centers and regional directors.
In order to find out why this was happening, as explained before a purposive sample namely a focus group discussion was conducted among the visiting academics of the regional centers including Colombo. They were divided according to the disciplines they were teaching, namely Sociology, Mass Communication, Economics and Political Science, and ended up with a general discussion among representatives from each group sharing their ideas in a common assembly. The discussions were conducted and monitored by the senior academics who were teaching in the main regional center, namely in Colombo. Thus, four groups were formed and in each group there were 10 to 12 members men and women. It should also be mentioned that some of the visiting academics happened to be former students of ours, namely the open university who had obtained a degree in Social Science in previous years. Therefore, they were able to represent aptly the perception or the views of the students, since they, themselves had gone through studies using distance mode. Following are some of their perceptions about student drop out and discontinuation of the studies after one or two semesters.

\section{Result and Discussion}

Almost all focus group members agreed that most of the enrolled students experienced "loneliness" and most of the symptoms were mentioned by previous researchers in the literature review. As expressed previously in the introduction of this paper, distance learning implies a physical separation between students and instructor. One of the views expressed in the focus group was that this 'physical separation' creates a real challenge for some of the students who might need or desire academic or technical support, and it quickly becomes a source of frustration. Another point mentioned was that due to the large numbers enrolled 'feedback' given by the academics was getting delayed and it affected adversely in their studies. Since there is no face to face contact with teachers, students have trouble in selfevaluation.. The situation has become worse due to the suppression of cadre positions at all levels during the past few years. Due to the medium of instruction "English" recruitment of qualified academics was difficult especially in the remote regional centers specially in the North and East. The so called "feedback" factor also affects commitment by the students. A traditional classroom, environment usually carries with it a certain level of social pressure. Namely the teacher and other classmates, expect each student to come to class every week, complete the assignment, answer the teacher's questions and actively participate in group projects. Ideally these behaviors should be there in the distance -learning class as well, but the social pressure to comply is absent since attendance is not compulsory. Use of traditional transmission model of communication, by the academics that were trained in conventional universities was another negative factor that demotivated some student's especially adult students. Since face to face sessions were reduced due to the introduction of new forms of technology, and for reasons of cost cutting most students were left to study on their own without any guidance. Family problems, including family commitments and constraints in the work place was another reason for dropping out.

Some said they were able to survive as students due to the support given by either husband/wife and, encouragement of their peer groups, who made a point to meet regularly in the university premises. However, in the past few years, this type of meetings were not encouraged or totally stopped in all centers due to short sited administrative blunders made by a previous administrative officer due to his lack of experience in distant mode education. This was also mentioned as a reason for drop out. Further some of the visiting academics who were interviewed 
mentioned that dissolving of the student councils, lack of recreational facilities were also a factor affecting drop out and dis-continuation of studies. Another view expressed by most of the visiting academics was that lack of computer literacy and fear of technology specially among the older students was another reason of dropout. Using a computer even to type a assignment was difficult for some of the adult learners. Some students did not know even to use a type writer properly. Most did not have even an e-mail address. Ushering of new forms of technology did not over come the embedded "distance" factor in the distant mode. According to the answers, given by focus group members, one of the main disadvantages, of distance learning is the absence of Social Interaction among students who are enrolled in distance learning programs. Unlike in the conventional universities, students often miss the aura of social interaction with teacher and their peers. Another draw back mentioned is that distance learning is an inappropriate format for everyone though many like to enroll. Due to lack of places in the conventional universities in Sri Lanka, of late, there is a tendency in younger people to enroll on the degree program offered by the department, pre-supposing, that just as in the conventional university, teaching method of the open university in Sri Lanka is also based on the traditional transmitting model. However, this proves that not everyone is suitable or prepared for enrollment in correspondence programs especially if a person tends to lag behind their work, lacks motivation and requires individual coaching from his/her teacher. Another important point mentioned in the discussion is that in Sri Lanka, there is a very strong tuition culture, where ordinary level students, and advanced level students pass competitive government exams due to strong doses of tuition almost in all subjects. In most of the tuition classes, probable answers to the popular public exams are dictated word to word by the tutors. Due to lack of places in the conventional universities or fear of ragging, there is also a tendency among the young people to select the open university, as a path way to their higher education without understanding the method of teaching. However, as mentioned, some students learn only when they are physically present in the class and assimilating all the information personally and with the help of peers. There is also a misunderstanding among some of the students is that Online degrees are inferior to the degrees offered by the conventional universities. This type of wrong perceptions or negative attitudes could reduce the motivation of teachers and as well as academics. In order to correct this wrong perceptions the department, needs to ensure the quality in content and delivery of distance learning courses that matches with the regular conventional campus classroom learning. However, this has not happened adequately due lack of staff members and suppression of cadre positions during the past few years. As a temporary measure, of acute staff shortage at all levels, the department had recruited some temporary graduate assistants but due to the temporary nature of their jobs many have not lasted working and left the job when they found a permanent job elsewhere. It is a fact that every time when one leaves, the department new recruits have to be trained again and this has happened constantly and had become a burden to the department.

With some of above serious concerns on how to address the physical separation between student and instructor, which is the base of distance learning, in addition to the new innovations already mentioned though in a limited way, "video conferencing" was tried out. Many stated that specially in the regional centers, due to lack of equipment there was not much interaction, except raising of hands by the students. It is a fact that an effective distance learning class need to incorporate interactive tools, when introducing educative tools such as discussion boards, wikis and blogs, and synchronous audio or video components. However, even with limited interactive tools used in blended online courses, only few students took the trouble to make use of them. Another important point that came from the focus group discussion was that, no body likes to take few courses at their own pace which is one of the key characteristic of distant mode of teaching. The commonly expressed view of the focus group was that, almost all wanted to finish the course as soon as possible and get the degree. One reason for this was that since most of the students who joined the social science degree was relatively young, they all wanted to finish the studies as soon as possible because delaying the degree means, if they are not married, post phoning of marriage, and losing the chance of getting a suitable employment, since jobs were scarce commodity in Sri Lanka.

\section{A Way Forward}

As solutions to the problems of student drop outs and increasing incomplete of required courses the following points were suggested by some of the focus group members. Introducing a retention system, such as keeping a reasonable deposit charged from the students, and reimbursing with the interest when they complete their graduation, or a kind of point system or reward system based on the completing of required credit courses, slowly moving away with transmission model of teaching, more and more participatory, and interactive teaching sessions, and increasing of personal contacts with tutors and peer groups. Many agreed that new forms of technology is useful and promising but problems with equipment and lack of adequate equipment and infrastructure need to be attended to before trying out new innovations, and visiting lecturers and regional directors and technicians need to be properly prepared and instructed on the use of new technology. Since timely "feed back" is a necessary component in the distance mode of teaching, it was suggested to minimize the delays by using colour codes for different subjects so that they are sorted out quickly and given to the tutors for marking and make arrangements to give eligibility marks as soon as possible.

\section{Conclusion}

How do we bridge the gap of distance faced by the students? Are the new forms of technology bridging this gap or widening this? The opinions and valuable insights expressed in the focused group shows reasons for dropout and discontinuity of the degree may be due to problems of social presence, lack of feedback and interactivity, faced by the students, as well as other problems mentioned in details. It is no doubt new technology mentioned above as Web O2 technologies have worked well in many countries because of the available adequate resources, and other necessary infrastructures that suits the modern technology. However, the Open University of Sri Lanka has a long journey ahead before welcoming such innovations. This paper has further highlighted that stakeholders responsible for bridging the gap of distance embedded in the distance education for students are not only the department in which they are enrolled but the whole university, namely starting from a chief executive to a security guard. Unless there is synergy of all stakeholders working towards one goal, namely making the distant student and their immediate environment pleasant new forms of technologies are not going to be effective. As said by Greenberg, advancement in technology does not lead to effective distance education [31]. The best distance education practices depend on creative, well-informed lectures, tutors, instructors and student friendly academics and non-academic staff. As Palloff and Pratt aptly reminds "technology does not teach students; effective teachers do" [32], based on the above findings the department of social studies of the Open University of Sri Lanka, has to go slow in introducing 
Citation: Fernando T (2018) Bridging the Distance by New Forms of Technology-Supported Learning: Is it Enough?. Arts Social Sci J 9: 370 . doi: $10.4172 / 2151-6200.1000370$

new technologies, because they might widen the distance between students an the department instead of bringing it closer. As expressed and articulated in this paper there are other urgent needs that need immediate attention before we embrace new forms of technology.

Finally this research paper has highlighted the urgent need for further research on various aspects that have surfaced within focus group discussion. These are in fact an eye opener and challenge for all who want to fall in line with the vision and mission of the Open University of Sri Lanka, namely "To be the premier Open and Distance Learning institution in Asia through excellence, efficiency and equity in Lifelong Learning and "To enhance access to high quality, affordable and relevant education through Open Distance Education and ensure life-long learning opportunities to face challenges in a knowledge society."

\section{References}

1. Veletsianos G (2010) Emerging Technologies in Distance Education Athabasca University Press.

2. Bull G, Knezek G, Roblyer MD, Schrum L, Thompson A, et al. (2005) A proactive approach to a research agenda for educational technology. Journal of Research on Technology in Education 37: 217-220.

3. Cuban L (2001) Oversold and underused: Computers in the classroom Cambridge MA: Harvard University Press.

4. Anderson T, Whitelock D (2004) The educational semantic web: Visioning and practicing the future education. Journal of Interactive media in Education.

5. Burns A, de Silva Joyce H (2008) Clearly teaching: Explicit ESL pedagog in action Sydney: AMEP Research Centre.

6. Ellison NB, Steinfield C, Lampe C (2007) The Benefits of Facebook Friends: Social Capital and College Students' Use of Online Social.

7. Mejias U (2005) Movable Distance: Technology Nearness and Farness Ulise mejias'blog entry.

8. Peters O (1992) Some observations on dropping out in distance education. Distance Education 13: 12-21.

9. Delahoussaye M, Zemke R (2001) 10 things we know for sure about learning online Training 38: 48-59.

10. Hipp $\mathrm{H}$ (1997) Women studying at a distance: What do they need to succeed? Open Learning 12: 41-49.

11. Lake D (1999) Reducing Isolation for Distance Students: An On-line Initiative Open Learning 14: 14-23.

12. Okun MA, Benin M, Brandt-Williams A (1996) Staying in college: Moderators of the relation between intention and institutional departure. Journal of Higher Education 67: 577-596.

13. Rogers PH (1990) Student retention and attrition in college In RM Hashway (Ed) Handbook of developmental education New York: Praeger, pp: 305-327.

14. Meacham D, Evans D (1989) Distance education: The design of study materials Wagga Wagga: Open Learning Institute Charles Sturt University.

15. Suen HK, Parkes J (1996) Challenges and opportunities in distance education evaluation. Distance Education Online Symposium News (DEOSNEWS) Vol-6.

16. Galusha J M (1998) Barriers to learning in distance education

17. Moore M (1989) Three Types of Interaction. The American Journal of Distance Education 3: 1-6.

18. Hillman DCA, Willis DJ, Guanawardena CN (1994) Learner-Interface Interaction in Distance education: An extension of contemporary models and strategies for practitioners. The American Journal of Distance education 8: 30-42.

19. Shin N (2003) Transactional Presence as a critical predictor of success in distance learning Distance Education 24: 69-86.
20. Knapper C (1988) Lifelong learning and distance education. American Journal of Distance Education 2: 63-72

21. Wood H (1995) Designing study materials for distance students Occasional Papers in Distance Learning.

22. West LHT, Hore T (1989) The impact of higher education on adult students in Australia. Higher Education 18: 341-352.

23. Keegan D (1996) Foundations of distance education (3rdedn), London Routledge.

24. Race $P$ (2005) 500 tips for open and online learning (2ndedn), New York: Routledge Falmer.

25. Simonson M, Smaldino S, Albright M, Zvacek S (2003) Teaching and Learning at a Distance Upper Saddle River NJ: Merrill Prentice Hall.

26. Garrison DR (1997) Computer conferencing: The post-industrial age of distance education Open Learning 12: 3-11.

27. Rourke L, Anderson T, Archer W, Garrison DR (1999) Assessing social presence in asynchronous text-based computer conferences. Journal of Distance Education 14: 51-70.

28. Short J, Williams E, Christie B (1976) The Social Psychology of Telecommunications London: John Wilei and Sons.

29. Threlked R, Brezoska K (1994) Research in distance education In Wills B (ed) Distance Education Strategies and Tools Englewood Cliffs: Educational Technology Publications.

30. Hardy DW, Boaz MH (1997) Learner Development: Beyond the Technology Teachng and Learning at a Distance: What It Takes to Effectively Design Deliver and Evaluate Programs no 71: 41-48.

31. Greenberg G (1998) Distance education technologies: Best practices for K-12 settings IEEE Technology and Society Magazine pp: 36-40.

32. Palloff R, Pratt K (2000) Making the transition: Helping teachers to teach online Paper presented at EDUCAUSE: Thinking it through Nashville Tennessee.

33. Mc Knight M (2000) Distance education: Expressing emotions in video-based classes. Paper presented at the Annual meeting of the Conference on College Composition and Communication Minneapolis Minnesota.

34. Holmberg B (1995) The sphere of distance education: Theory revisited.

35. Cavanaugh C (2001) The effectiveness of interactive distance education technologies in K-12 learning: A meta-analysis. International Journal of Educational Telecommunications 7: 73-88.

36. Kearsley G (1996) Education as usual: Comments on Chris Dede's article. The American Journal of Distance Education 10: $55-58$.

37. Moore MG, Thompson MM (1990) The effects of distance learning: A summary of literature (Research Monograph No 2) University Park PA: American Center for the Study of Distance Education.

38. Wagner E (1998) Interaction strategies for online training designs Pape presented at the Annual Conference on Distance Teaching and Learning Madison W.

39. Gilbert L, Moore DR (1998) Building interactivity into web courses: Tools for social and instructional interaction Educational Technology 38: 29-35.

40. Sherry L (1996) Issues in Distance Learning. International Journal of Educational Telecommunications 1: 337-365.

41. Dibiase D (2000) Is distant education a Faustian bargain? Journal of Geography in Higher Education 24: 130-136.

42. Sharon S, Michael A Susan Z (2005) Teaching at a Distance: Foundation of Distance Education learning.

43. Trudie Frindt (2005) The impact of video conferencing in distance education.

44. Valentine D (2002) Distance Learning: Promises Problems and Possibilities Online Journal of Distance Learning Administration. 